\title{
The evaluation of interdisciplinary learning initiative in managing depression
}

\section{Summary}

This paper reports the findings from a descriptive study exploring community-nursing students' experiences of interdisciplinary learning on managing depression. The study was completed as part of a specialist module workshop included in a post-registration community specialist practitioner programme. Questionnaire data included attitude ratings and qualitative evaluations of problem-based learning (PBL). A cohort of 34 community nurses responded. The findings identified issues relating to the learning process and its influence on the knowledge gained and attitudes to team work. Community nurses reported the workshop was thought provoking and the challenging issue is the different opinions of the district nurses role in managing depression from the perspective of the students. This study suggests that problem based learning had a positive impact on students' learning which makes it a well-received contribution to learning. It also reinforced the importance of healthy attitudes towards collaboration in promoting mental health practice. All of these do ultimately have implications for clinical practice.

Key words: Interdisciplinary education; problem-based learning; community nurses' attitudes, teamwork.

Nessie Shia, Lecturer Community Mental Health Nursing, Brunel University, School of Health Sciences and Social Care, Mary Seacole Building, Kingston Lane, Uxbridge UB8 3PH. nessie.shia@brunel.ac.uk

Veronica Bankole, Specialist Community Practice Teacher, Westminster PCT.

Hallfield Clinic, Bickering House, Hallfield Estate, London W2 6HF veronica.bankole@westminster-pct.nhs.uk

\section{Introduction}

The government's vision to deliver first class health services through the National Health Service (NHS) has presented a great challenge for health care professionals. The shift in emphasis from institutional to community-based care will require a welleducated work force to be at the heart of high-quality service delivery and multi- 
disciplinary and multi-agency working is consistently a key to delivering optimum and appropriate care (Department of Health 2001, Wanless 2002). The challenge to improve public health and patient care is multi-disciplinary and the aims for a flexible health care workforce engage in teamwork, partnerships and joint working between patients, agencies and professions. It also requires flexible working without rigid professional boundaries, provides opportunities to alter training pathway and the development of new and hybrid types of health care workers (Department of Health 2000).

The commitment made in the recent government white papers, Choosing Health (DOH 2004) and DOH (2006), reinforces the importance of working in partnership to promote mental health and well-being for the nation, In addition, the World Health Organisation's recent message (WHO 2004) stated that mental health and mental well being are fundamental to the quality of life and productivity of the individuals, families and communities. For the individual to be active and creative, being in a state of sound mind and body is essential. To achieve these goals, it is crucial that health care professionals and medical allied agencies work in partnership between and across various disciplines and professions (Our Healthier Nation, DOH 1999, The NHS Plan, DOH 2000). As this proposed way of working together is fairly new to the professional involved, various teaching and learning initiatives were introduced to support the drive.

Inter-disciplinary learning is increasingly becoming the characteristics of universities. The approach of sharing learning is embedded in the Community Health Nursing Specialist Practitioner Course at Brunel University, West London. The overarching aim of the course is to deliver learning and teaching strategies to promote and augment the students' ability to think critically and creatively. As part of their preparation for working within the multi-disciplinary teams in the National Health Service, the programme offers students with opportunities for interdisciplinary shared learning in all three of the four modules and to study aspects of research, public health promotion and management of change in practice that will further develop their professional expertise. This study examines the experience of interdisciplinary learning in a specialist module using a mixture of educational strategy including didactic and highly interactive teaching, problem-based learning (PBL) using a case study to stimulate discussion on management of depression. 


\section{Background Literature}

One of the distinguishing factors of inter-disciplinary practice is teamwork and sharing learning in small groups. Interdisciplinary teams are usually in small groups. Engaging with small groups especially for learning purposes is mostly interpersonal and interactive in nature. It is an appropriate and challenging method of enabling students to be both learners and collaborators in their own intellectual, personal and professional development. There is strong evidence from students that learning in small groups is of a great benefit and an enjoyable experience (Luker 1989, Griffiths, Houston and Lazenbatt 1996), as they not only have a sense of belonging and participation but also are actually involved in the group.

A small group is viewed as an ideal mechanism for exploring and developing a range of key skills. These include communication skills by utilizing a range of approaches, also information management skills, team/group working, ethics and recognition of diversity, time management, personal responsibility and ability to continue to learn. It is within small groups that self-confidence can be improved and teamwork and interpersonal communication develops. As reported by Griffiths et al (1996), development of small group work and other skills gives students the opportunity to observe their own learning styles and change these styles to suit different tasks and engage more deeply with the content of their subject. These are pre requisites for a deep approach to learning as well as attributes for shared or interdisciplinary learning. Small groups are used extensively and in many different ways and it has been found useful for problem-based learning (PBL) approach.

Problem based learning (PBL) has its origins in medical education in Canada, USA, Netherlands and Australia some 25 years ago and it has since gain popularity worldwide. PBL or case based learning has become widely used in professional education and is now being adopted by nurse educationalists as a part of their teaching strategy (Nursing and Midwifery Council, 2004). There are many definitions of problem based learning but the concept is to encourage learners to actively participate in seeking the whole picture, engage in reflective practice and evaluation with self, peers, groups and exploratory ways in order to make sense of new ideas and experiences' within the learning process so deep learning will occur (Biggs, 2003; Biley and Smith, 1998, Marshall and Rowland, 1998). 
Wilkie (2000) suggested that the principle behind PBL is that learning is based on experiences that reflect real situations. Students are encouraged to take control over the learning process as they collectively make decisions about case scenario through interactions (Carey and Whittaker 2002). This approach builds on humanistic learning theory and aims to address both cognitive and affective dimensions of learning; it also increases the potential of theory and practice integration. Schwartz (2004) endorsed this approach, as graduates from PBL courses are prepared for a lifetime of learning and discovery, more motivated and satisfied with their education.

The purpose of introducing problem based learning into the design of teaching community health specialist practitioner students is to improve the quality of student learning processes with the hope that students are able to apply theory to practice, value the opportunity to share experiential learning and common goals thus contribute to improve the appreciation of multi-disciplinary and collaborative working. Macdonald (1996) suggested that PBL also requires students to develop a whole range of skills to enable them to learn effectively such skills are information sharing, team working skills, communication and most importantly high order cognitive skills for professional development. It is the type of key skills that are value by most employers.

Wisker (2002) suggested that some of the strategies of problem-based learning, which release creative energy in the learner, could usefully be transferred to and engaged with in research. It is therefore advocated that student-centred case based learning has much in common with PBL for maximising the effectiveness of interdisciplinary education (Miller et al., 2001).

\section{An Example of Specialist Module}

The topic of "Management of Depression in primary care" was timetabled within a specialist module since it was felt to be a health need relevant to most students and likely to engage them in debate and learning in a workshop. Depression is a common mental health disorder in primary care throughout the world and WHO predicted that by the year 2020 depression would be the second most important cause of disability after cardiovascular disease worldwide (WHO, 2007). The session on depression management provides an ideal environment for interdisciplinary sharing learning as it 
provides a safe environment for students in which to learn, reflect on their clinical experiences without all the demands and stresses of the real clinical setting.

\section{Research questions}

Both lecturer and Specialist Community Practice Teacher (SCPT) are specifically interested in enhancing students' base knowledge of managing depression through interdisciplinary learning. The Specialist Community Practice Teacher (SCPT) is an experienced clinician in a specific discipline of nursing and is a link between the University and practice for students. The research questions were identified as:

1. Is Problem Based Learning (PBL) an effective teaching method to facilitate interdisciplinary learning?

2. What are the nurses' experiences of interdisciplinary learning in managing depression?

\section{Method}

A descriptive study of students' experiences was used to evaluate the use of PBL within a single specialist module of the community degree programme. A questionnaire was chosen so that all students had the opportunity to participate in the research. A pre and post questionnaire and response statements were collated from a sample of 34 students before and after interventions. A 16-item self-reporting statement arranged in Likert-type scores was adapted from the Interdisciplinary Education Perception Scale (IEPS) (Leucht 1990) and Problem-Based Learning Attitude Questionnaire (PBLAQ) (Reynolds 1997). The Interdisciplinary Education Perception scale (IEPS) measures the professional perceptions of competence, perceived need for inter-professional collaboration, perceptions of actual interprofessional co-operation and attitudes towards the value of working with other professions. The scale claims content validity and boasts a Cronbach's alpha coefficient of reliability value of 0.87. Furthermore Hayway et al. (1996) indicated that IEPS was helpful in identifying changes in students' attitudes towards one another following their involvement in a practice-based inter-professional course.

The Problem-Based Attitudes Questionnaire (PBLAQ) is a tool to encompass both intellectual and social aspects of the learning experience. The PBLAQ had an 
accepted internal consistency (Cronbach's alpha $=0.73$ ) justifying use of a total score (Reynolds, 2003).

Additionally, to counter the shortcomings of the survey, a second method using qualitative data collection from respondents' comments and non-participant observation notes from both lecturers were collated to check cause and effects of interdisciplinary learning. This method allows a comprehensive analysis, and strengthens reliability and validity; concerns / issues and also to provide complex insights on interdisciplinary learning. Permission to proceed with the study was obtained from the University Research Ethics Committee.

\section{Data collection and analysis}

The questionnaire contained a mixture of attitudes measures, knowledge gained and their perceived learning styles. Each statement is responded to according to a fivepoint Likert scale, with strongly disagree and strongly agreed at opposite poles. The questionnaire was piloted before the actual study. All the questionnaires were completed anonymously to protect the interests of student respondents and students were also informed of their right to withdraw from the study. No students declined to participate. Students were required to complete the pre workshop questionnaire as it was assumed that they have had previous exposure to depression management. Data from questionnaires were analysed using the Microsoft Excel database.

\section{The PBL task}

A convenient sample of 34 students participated in the workshop. The students who took part were mainly community mental health nurses, district nurses, health visitors and school nurses. Occupational health nurses were not included due to timetable constraints. The workshop took place in the autumn term and was the community nurses' first exposure to interdisciplinary learning. There were 4 males and 30 females and the average age range for female is 40.27 , male average is 31.5 .

After an initial aim and objectives of the workshop was outlined followed by didactic and highly interactive teaching, students were allocated into 5 groups of 7 mixed nursing disciplines and given a case study as 'trigger' with questions to identify essential issues to stimulate, debate and challenge during interdisciplinary interactions. Case studies are useful for their rich description and heuristic value and presents differing perspectives or opinions when used in interdisciplinary learning. 
The case study offers lecturers an opportunity to observe and probe the complexity of the discussions in a safe, unobtrusive distance. The student groups were allotted 45 minutes to brainstorm possible solutions, discussion among themselves and write their hypothesis; and interventions on the flip charts. At the end of the allocated time each group were asked to feedback with a question.

The lecturers circulated among student groups and acted as non-participant observers with field notes written to record the format of discussions and behaviour. Field notes were recorded in private to minimize disruption to the group. Observation is fundamental to all qualitative inquiry and has an important role as body language and affect were noted in addition to participants' words. In addition the lecturers learn about the meanings of participants' actions, their problem solving strategies; teamwork through listening to their discussions on the case study. The purpose of non- participant observations is to identify issues and pattern of interactions using a checklist as guidance to strengthen reliability and validity bearing in minds the criticisms of subjective bias (Cohen et al., 2000, Bell, 2005). The discussions and debates by different nursing disciplines around the case study presented challenges. The write up of notes occur the same day to clarify unfounded assumption.

\section{Findings}

The anonymous completed questionnaires from 34 students were collected. These were analysed together with qualitative comments and field notes summary to establish the existence of the relationship between variables.

The findings were presented in three categories, which were knowledge gained, individual attitudes to teamwork and the learning process. 


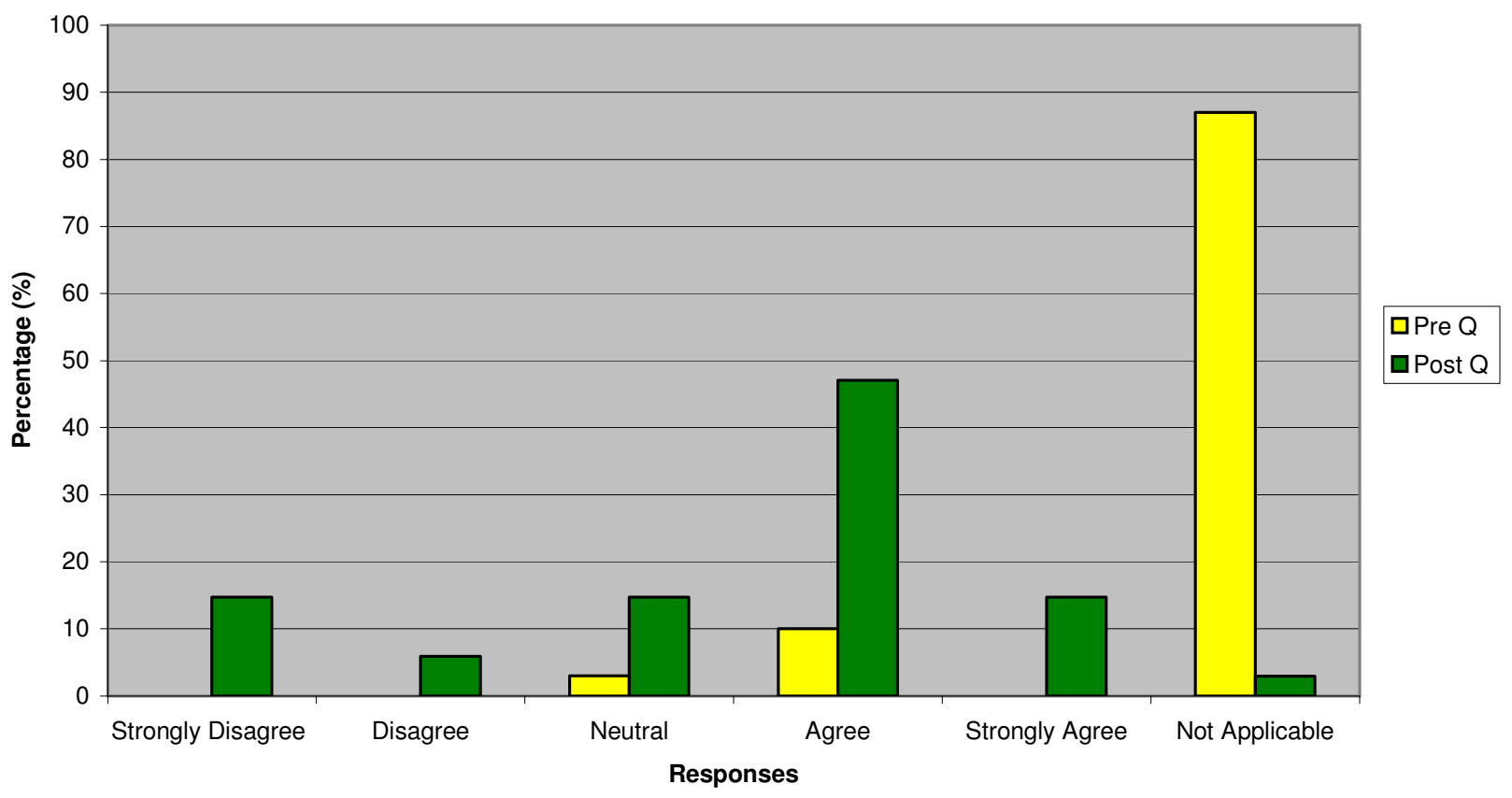

Figure 1 Positive contribution made to learning

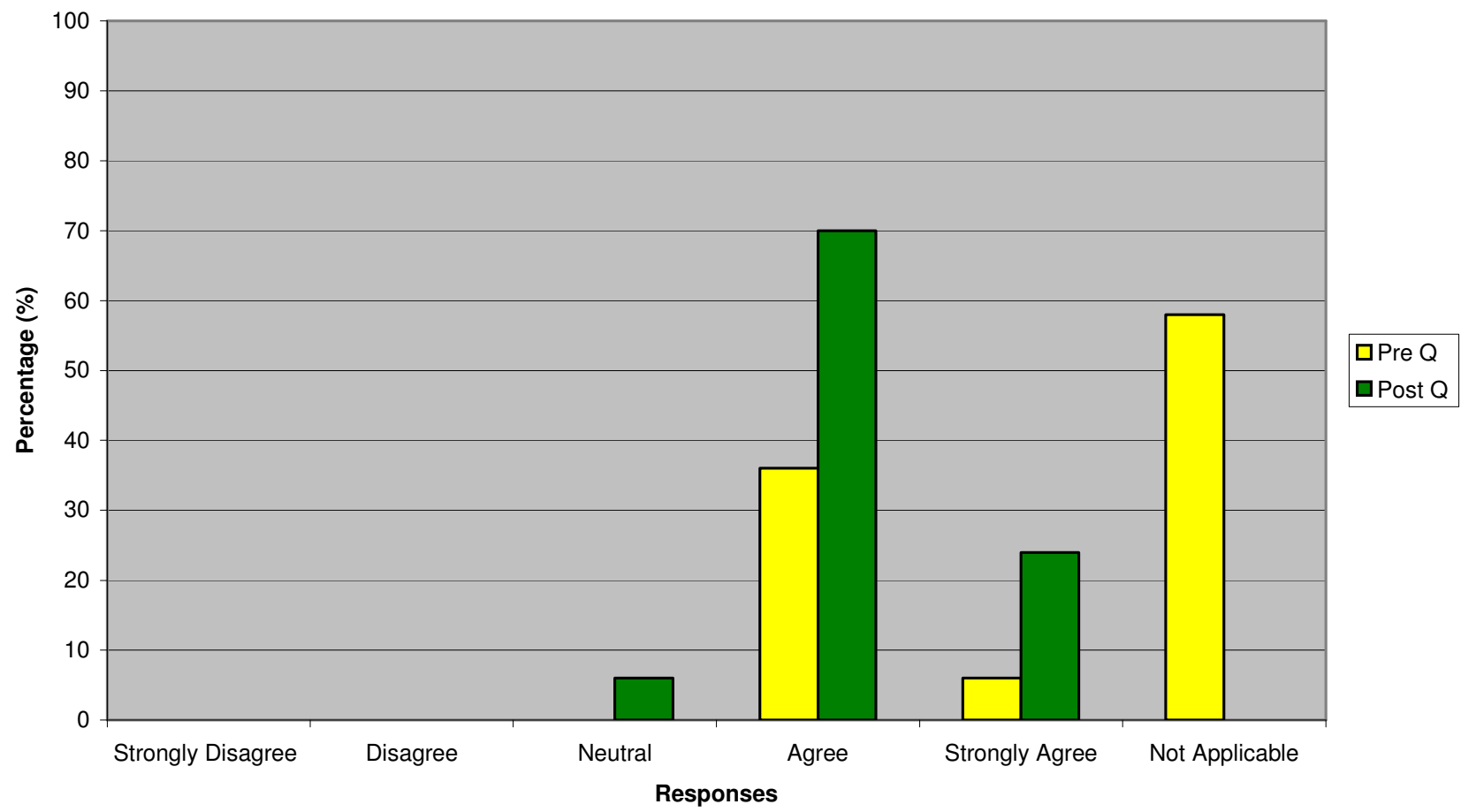

Figure 1.1 Level of knowledge gained on interventions of depression 


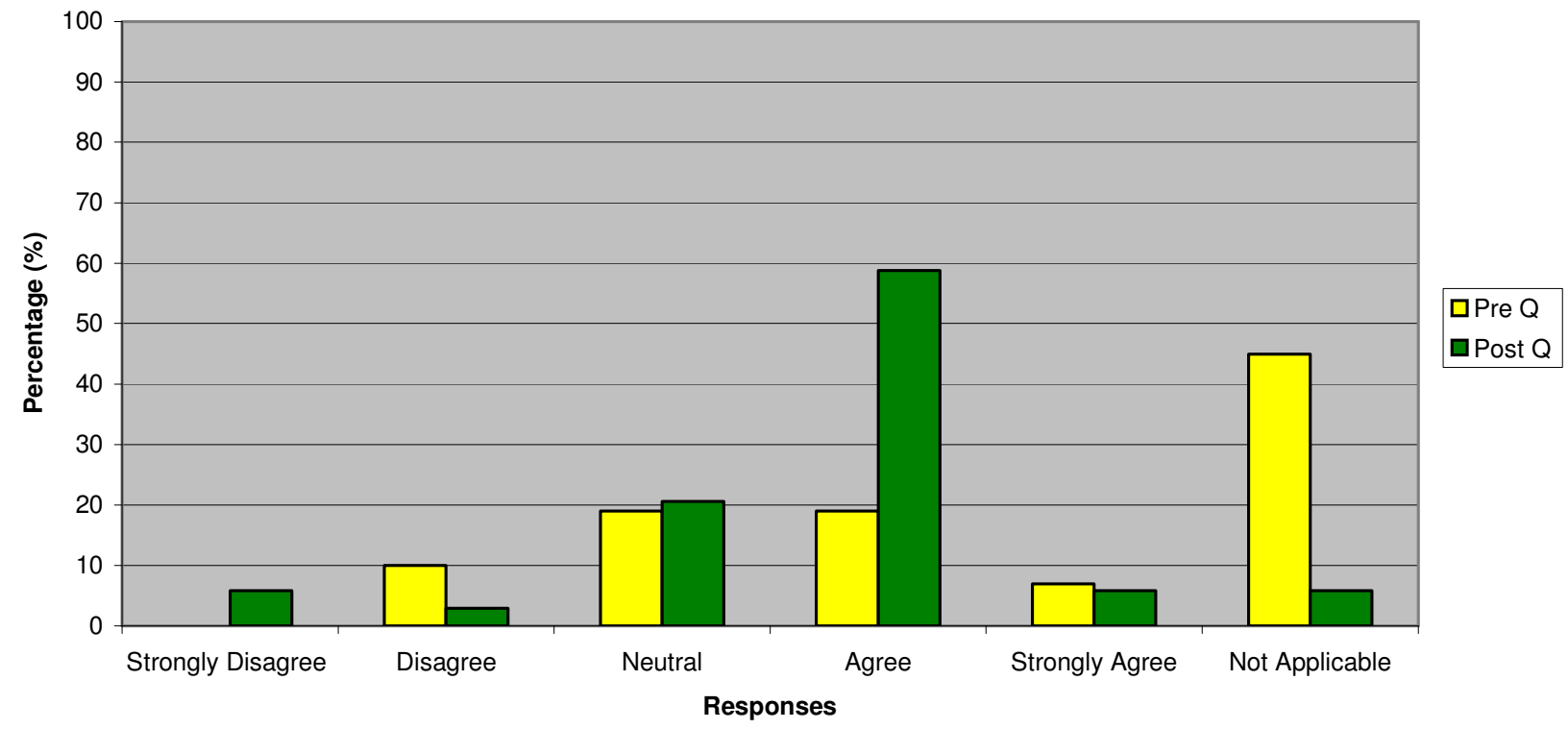

Figure 1.2 Students motivated by session for deeper learning 


\section{Knowledge Gained}

Participants were asked to respond to three statements on knowledge gained which were as follow:

Figure 1 I learnt a lot about interventions on depression from the case study discussion

Figure 1.1 I was able to make a positive contribution to the learning within the case discussion in the group.

Figure 1.2 The case based learning has motivated me to study further on the topic.

In Figure 1, 48\% commented that they have improved understanding on interventions of depression. In Figure 1.1, 70\% agreed that they had made positive contributions to learning within the group. Furthermore in Figure 1.2, 59\% of students agreed that the group discussions have influenced their motivation to study further on the topic. Field notes observation data indicated that this improved understanding was probably due to mental health nurses' (18\%) contributions to the discussion and sharing their expertise knowledge on management of depression with other group members. Respondents' comments explained that they had a better appreciation of what others' roles were and the need for better collaboration in team working for the benefits of mental health clients.

\section{Learning Process}

When reviewing students' responses from the questionnaire regarding the process of learning, two themes emerged, student perception of group work and experience of PBL.

The students were asked to rank three statements in the questionnaire on group work perception which were as follow:

Figure 2 I respect my fellow nursing colleagues' contributions in the case discussion

Figure 2.1 The interdisciplinary case discussion made me think more deeply about successful mixed team working. 
Figure 2.2 Discussion on mental health issues within the case discussion helped me to reflect on myself as an individual

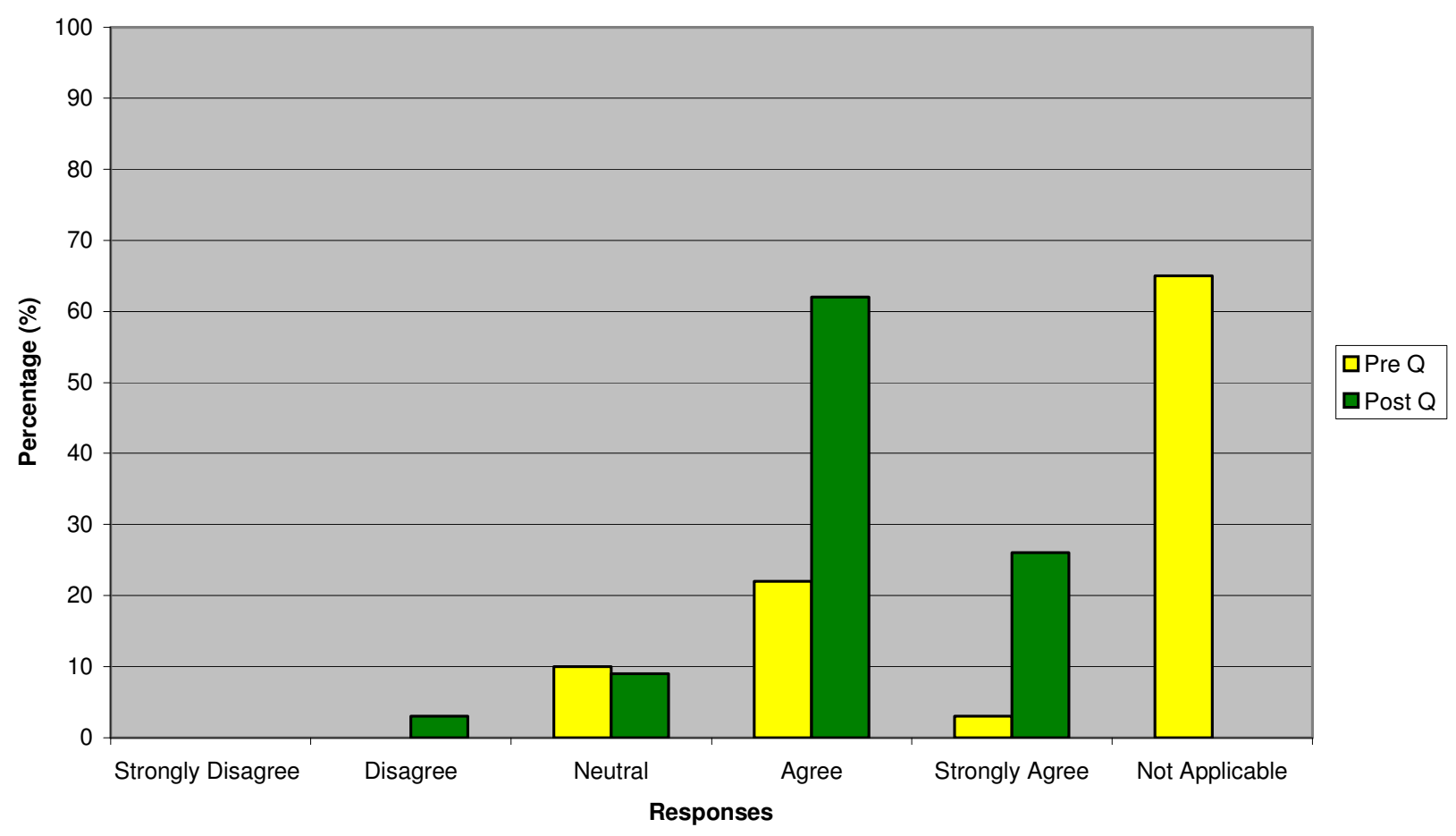

Figure 2 Students accorded colleagues more respect for contributions 


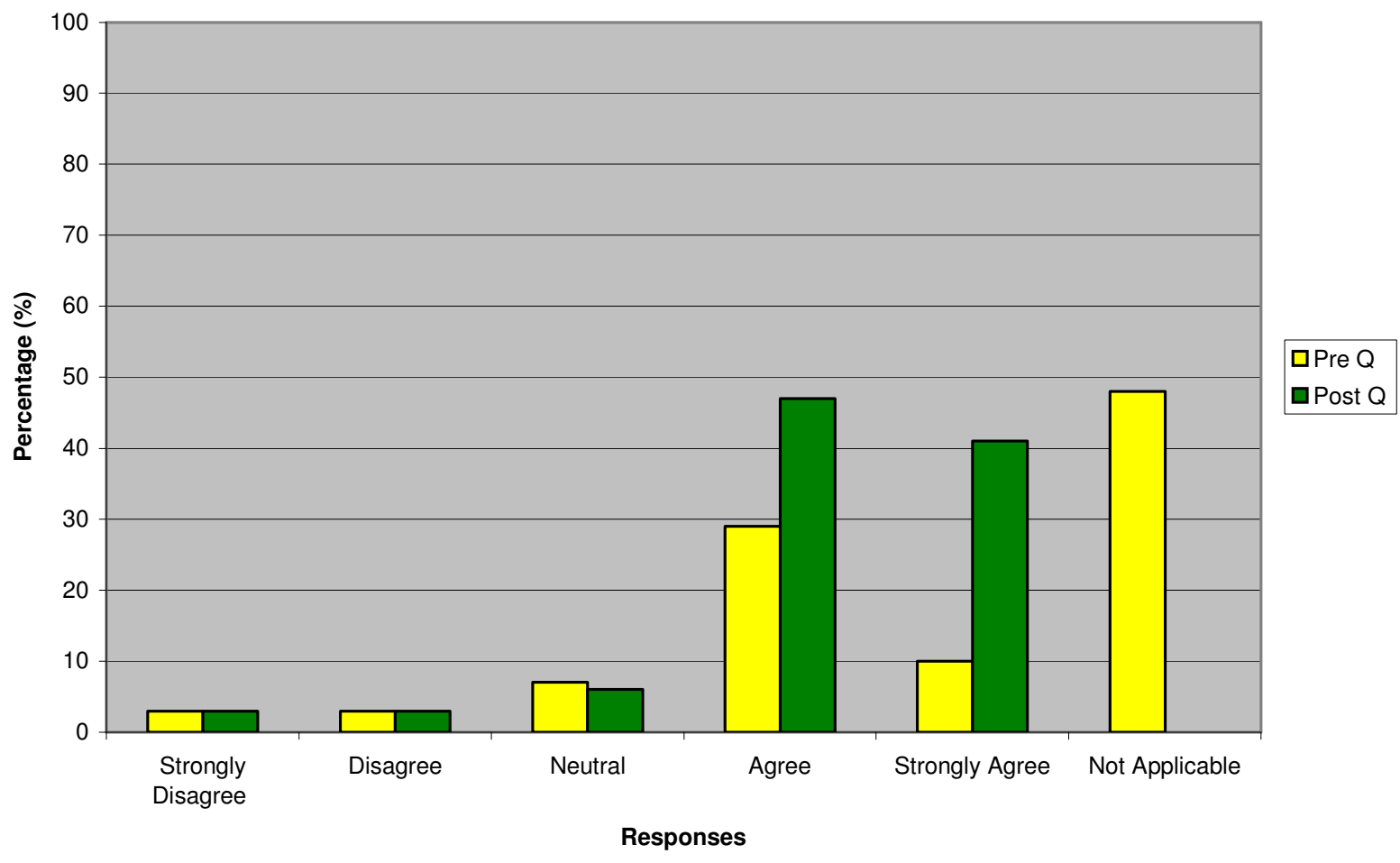

Figure 2.1 Students' perception on success of mixed team working 


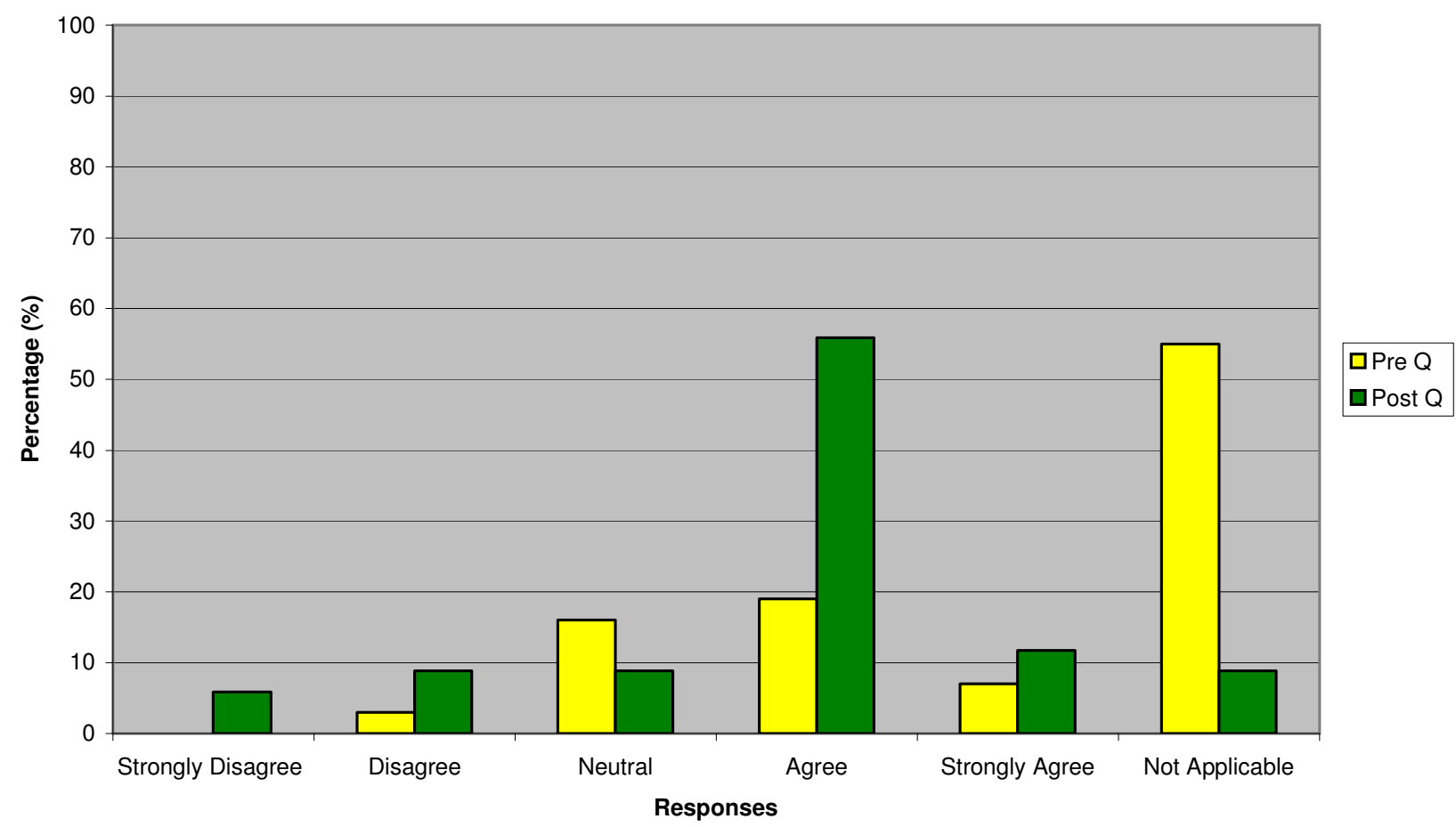

Figure 2.2 Discussion on mental health issues have positive impact on students' attitude

\section{Perception on Group Work}

Figure 2 showed that $62 \%$ of students claimed to have high regard for fellow nursing students' contribution to the discussion while in Figure 2.1, 47\% of students' perception of group work is very positive. Additionally, in Figure 2.2, 56\% of students agreed that the discussions on mental health issues had helped them to reflect on their attitudes. This makes them good team players and collaborators in team working. The real case study helped to identify situations relevant to all students which had impacted on teaching. By contrast, the comments recorded that most students have not only enjoyed working with nurses from another discipline but have had the opportunity to understand their role in primary care. However, the comments recorded from district nurses seemed to contradict the findings as they indicated that there was confusion regarding their roles and there is a need for further clarification. This concurs with field notes observation that there were lots of heated debates during group work on district nurses' role regarding referral criteria to the team from other services and their role in preventive care. 


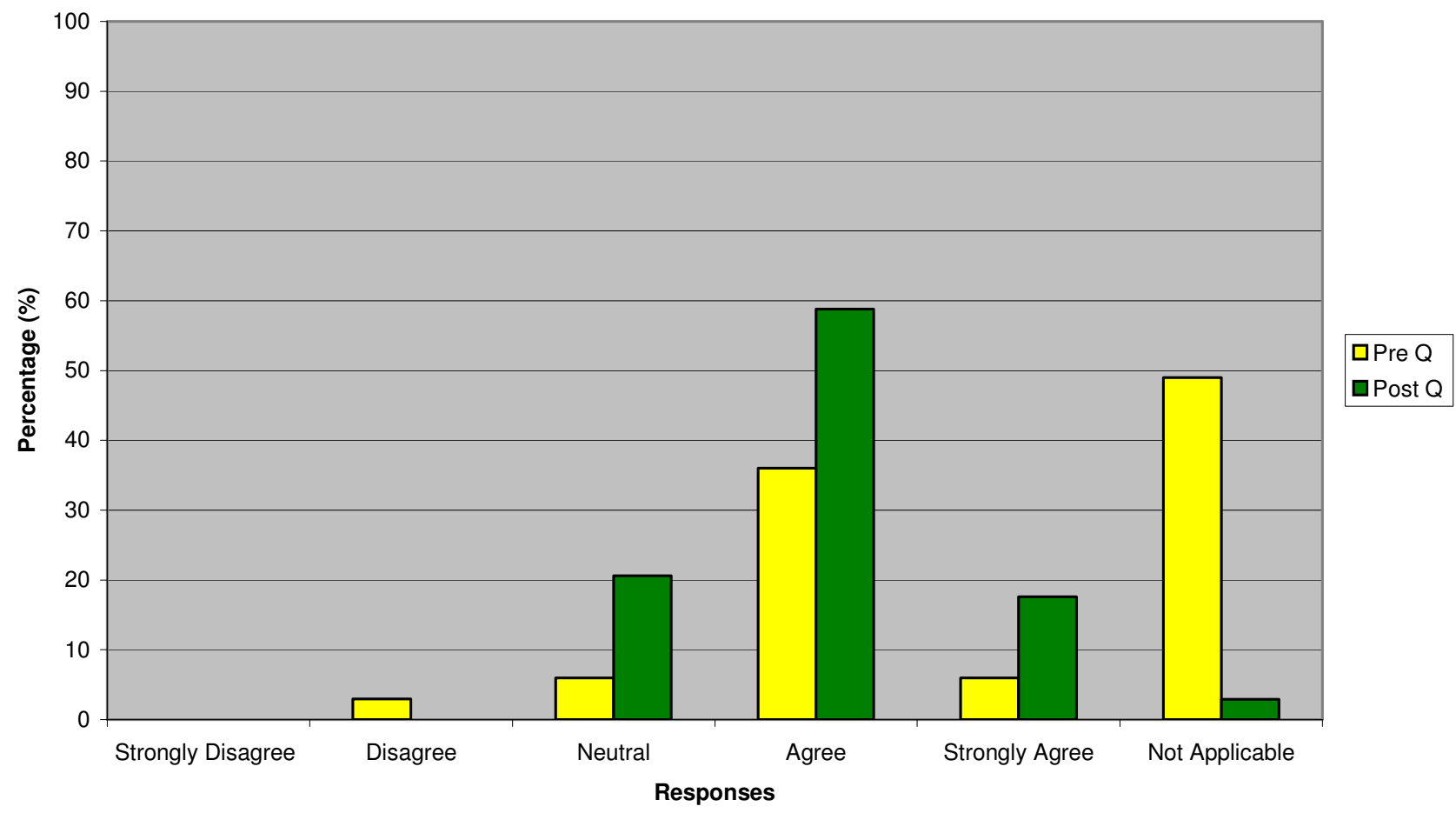

Figure 3 Students' responses on the responsibility of case-based learning

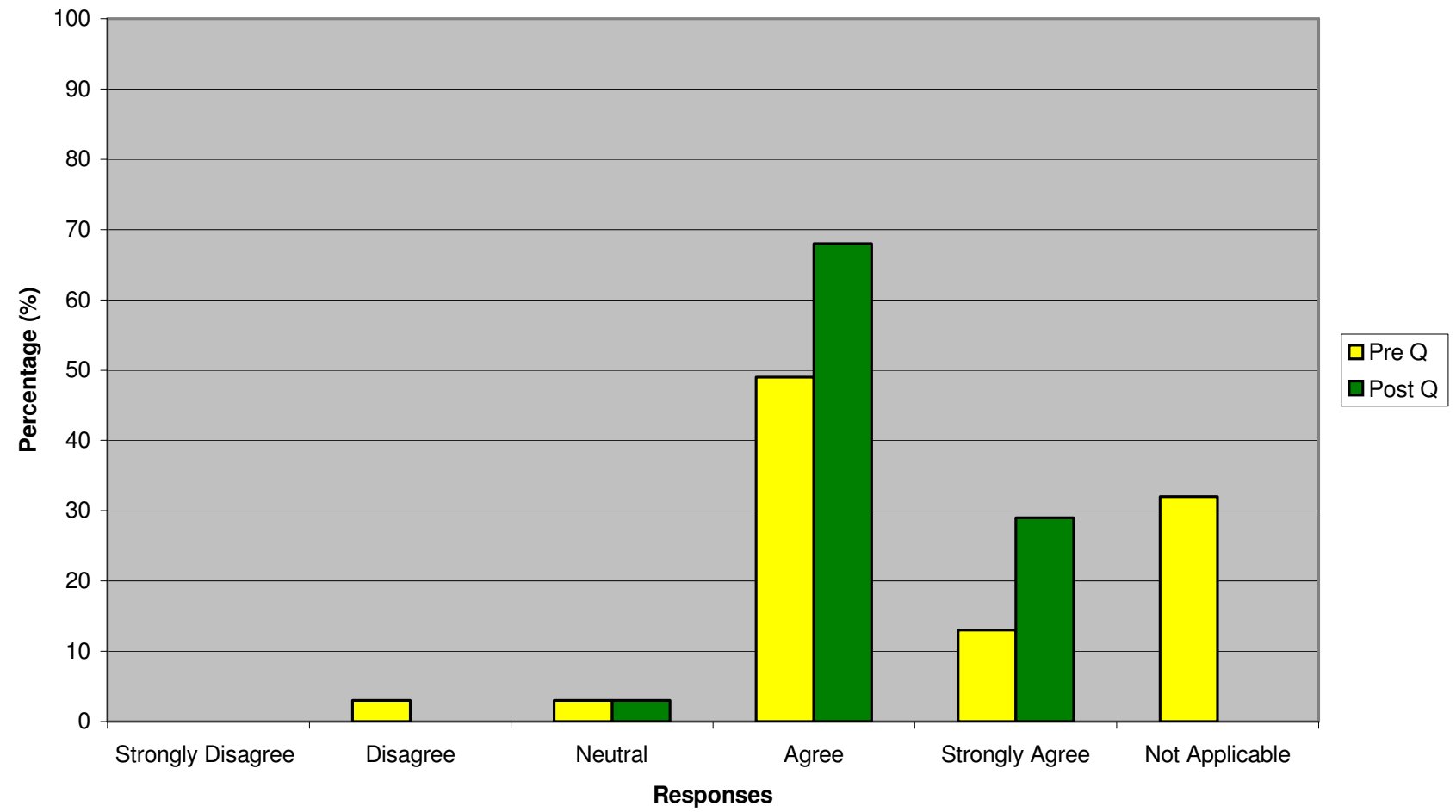

Figure 3.1 Students enjoyed working with other discipline and understood their role 


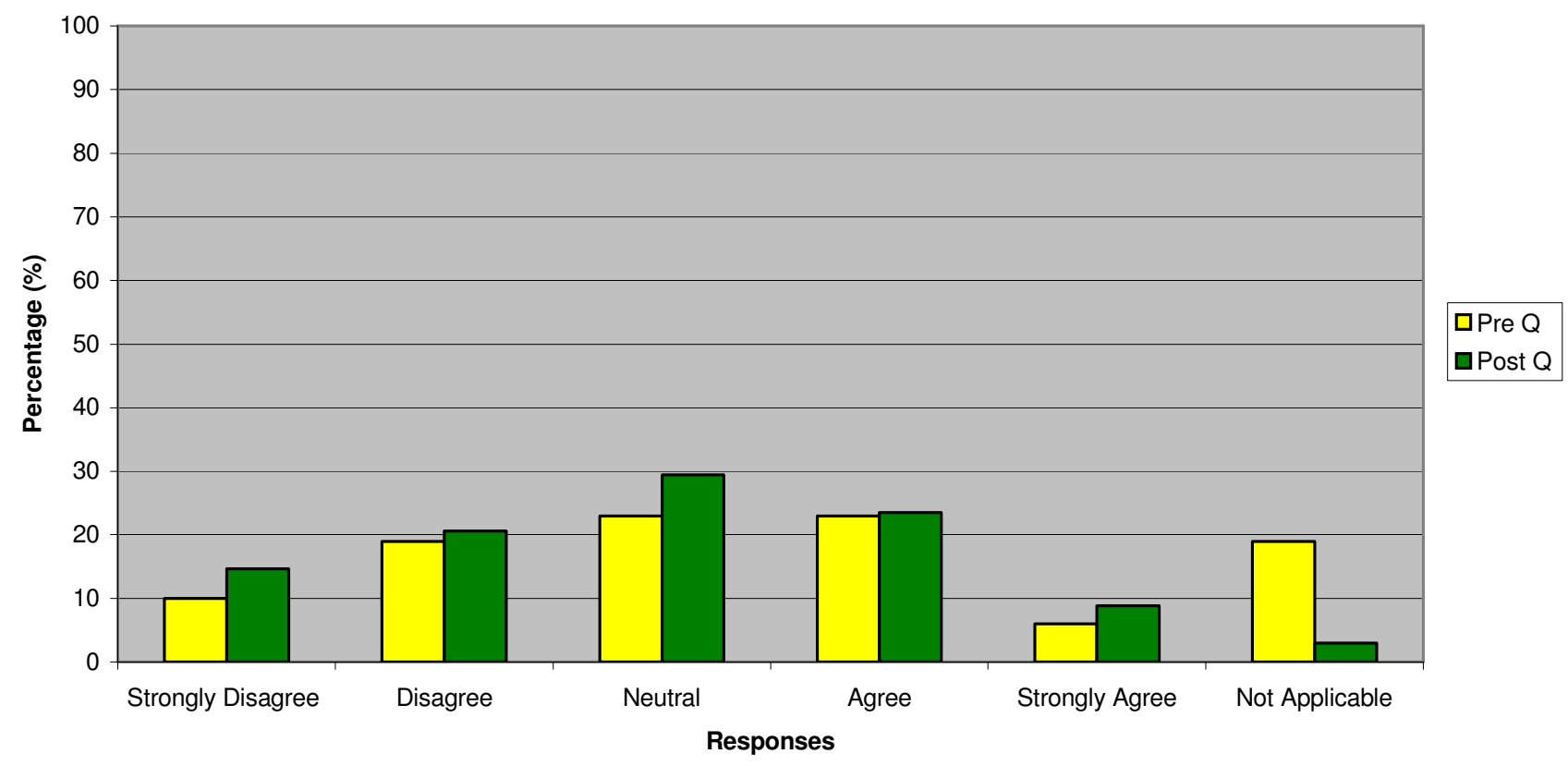

Figure 3.2 Indication of learning styles preference by students

\section{Learning from PBL experience}

The three statements on learning styles preference were:

Figure 3 I enjoyed the responsibility of case based learning.

Figure 3.1 I enjoyed working with students from another nursing discipline and understood their role in primary care.

Figure 3.2 I prefer lectures to case based learning.

In exploring whether students would prefer PBL, 59\% have enjoyed the responsibility of case-based learning or PBL as demonstrated in Figure 3 and $68 \%$ of students were in agreement that they have enjoyed working with other discipline and understood their role in primary care as demonstrated in Figure 3.1. By contrast in Figure 3.2, only $29 \%$ stated that they would prefer these types of learning instead of lectures. The record from the field notes observation indicated that some nurses experience of the group dynamics that was evident from non-verbal communication that seemed to indicate disagreement and tension, for example, tones of the voice, hand gestures, 
facial expressions and bodily movements showing unease during group work. Despite the process of dealing with disagreement, the majority of students

were positive about PBL. Within the comments collated, nurses expanded on this theme by identifying the value of having the opportunity to explore with peers real practice issues, suggesting that it was during the session that theoretical perspectives could come alive. Student comments include:

"Mixed group disciplines working and interacting together very beneficial to learning".

"Opportunity to discuss real case study".

"Learning styles were beneficial and thought provoking than lectures".

The comments seemed to suggest that students were going through an experiential learning process (Kolb, 1984). It is possible that the opportunity to examine real life practices in-group discussion meant that students were confronted with what Gibbs (1988) identifies as a concrete experience. The participants acknowledged that how they could learn from sharing knowledge and working together that was understood to be a key feature in aiding the acquisition of knowledge relevant to practice. Observation notes confirmed that one factor possibly contributing to how PBL was enjoyed by students as opportunity to learn more about the roles of different nursing disciplines, and the chance to find out more about a patient's illness in depth.

\section{Discussion}

This small-scale study identified factors that have been categorised into three themes emerging from both quantitative measures of PBL and qualitative comments and observation notes. The themes included students' acquired knowledge as an outcome of educational interventions, experience of PBL, understanding of professional roles, and teamwork. The findings suggested that community-nursing students have gained knowledge and shared experiential learning experiences from interventions on depression that were used in the group work interactions. The 'experiential learning' raised awareness and understanding on how different professional working together for a common purpose with their different complementary contributions to people with depression and skills for a joint care plan to be put into action for the benefits of patient or client care. Furthermore the discussion on mental health issues had a positive impact on community nurses' attitude to develop close working relationships 
with other nursing colleagues with the aim to develop strategies to defeat depression and remove stigma. The case study used in the group work motivated community nurses to study further on topic of depression to improve their skills and knowledge on the subject.

The workshop was successful in enabling nurses to reflect on the roles of other nursing disciplines, as well as, their own contribution to patient care in clinical practice which will enhance professional working relationships as was reported in the literature by Conner and Reeves (1997). It would appear that teaching in the workshop had a place to promote adult learning that enhanced learners' interest and goals, connected with prior knowledge, focused on real problems in a participatory process, engaged in reflective practice and learning based on mutual trust and respect. The study provides some indication of the relative merits of classroom interdisciplinary shared learning which enabled transference of theory and practice.

The findings of this brief experience of PBL were helpful for building multidisciplinary team working as cited by Latimer et al. (1999) and Reynolds (2003) and how a useful vehicle to break down professional boundaries.

The study findings suggest that successful IPL takes place where subject and content are relevant to all nursing disciplines with direct application to clinical practice as reported in the findings similar to Morrison et al. (2003). It could then be argued that IPL are considered effective in promoting teamwork, focusing on collaboration and reducing competition among team members (McPherson et al. 2001).

To understand collaborative working is fundamental to effective community nursing practice that is increasingly becoming a requisite for quality care. PBL used as a teaching strategy promoting shared learning and collaborative decision- making which are beneficial for clinical practice. The learning environment is ideal to foster reciprocal behaviour in students and if mirrored in practice should contribute to effective multi-disciplinary teamwork as suggested by Darvill (2003). The results form this study has demonstrated that the principles of pedagogy have been used to provide an opportunity for effective interactions and active learning amongst students. Furthermore, nurses need to acquire effective communications skills that were highlighted during the workshop to encourage a team approach. Effective communication is vital to improve teamwork and ultimately patient care. It is also equally important to understand each other's roles in order to make an effective contribution to the multi-disciplinary team (Nicol and Chaput de Saintonge 2002). 
While the literature on teamwork in health care has tentative findings for improving patient outcomes as suggested in Poldre (1998) and Barr (2002), there are reports that barriers such as attitudes and behaviour still hinder teamwork and this include a lack of knowledge about the roles of different health professionals which still exists. This finding was supported by the results of our study. Eccles (1996) asserts that attitudes and behaviour resistant to change emanate from the anxieties about losing their traditional habits and privileges, Close and Cheater (1994) further suggest that changing clinical attitudes and behaviour are major challenges facing the development of evidence based practice and those who work in the mental health services.

Students inferred that learning became motivating when conducive environment factors allowed them to share practice experiences with peers as well as reflecting on them. In this way students can share their learning experience with peers who are inexperienced in the PBL method. In addition working together enabled nurses to share expertise and knowledge, and also provided opportunities to develop networks (DOH, 2001). The role of both lecturer and specialist community practice teacher influenced these characteristics and therefore the learning process. However, when the environmental factors were in conflict with personal characteristics learning ceased to be effective particularly the poor group dynamics that was being observed and recorded in the field notes. Conflict or disagreement is part of every life of any group work interactions. It can have a negative effect and differing opinions regarding personal and professional values (Elwyn, 2001). In this respect, the skills of the facilitator are important to clarify directions and resolve conflict.

The results from the scales questioning students about their responsibility of case based learning and about their sense of enjoyment suggested that these two factors are positively correlated and students tended to indicate high scores for case based learning, this result was similar to published findings in (Carey and Whittaker 2002, Reynolds, 2003).

\section{Implications for Practice}

This joint PBL initiative conducted by both lecturer and Specialist Community Practice Teacher (SCPT) provided a role model for students in term of collaborative working. The SCPT has the unique role and opportunity to facilitate shared learning between health care workers from various disciplines thus bridging the theory and practice link. The role is particularly useful in inter-professional education where 
many disciplines are involved. This position can be used in prompting and guiding students in practice to use knowledge acquired in the classroom on certain health conditions and its management. The knowledge acquired on effective communication, team and collaborative work will be utilised to help educate other students by setting up inter-disciplinary and interagency meetings to give appropriate care and seamless service. PBL and teaching methods do have implications for the training of SCPTs. As it is a fairly new method of teaching in nursing education, universities will have to review the current curriculum and ensure that it includes methods of using PBL to facilitate students learning. This could be a joint training initiative between nursing and social work for the potential development of practitioners who can overcome the health and social care divide in a holistic manner. Whether this leads to the development of a hybrid worker will be down to the workforce planners, employees and higher education institutions.

\section{Conclusion}

Community nurses are ideally placed to promote positive mental health and well being as demonstrated in this paper. Community nurses are in a key position to develop and deliver the public health agenda in line with current government policy. Nurses are also increasingly encouraged to work across professional boundaries, to become leaders in the climate of modernisation on healthcare. The acquisition of new knowledge and skills and the determination to extend their new role, community nurses could be pivotal in helping to reduce health inequalities across the country and promote health at the individual and population level.

Community nursing students valued their opportunity to share experiences with other nursing colleagues on mental health issues that contributed to their satisfaction with the course. Community nurses also came away feeling positive about learning and teamwork. PBL would appear to provide a useful vehicle for the promotion of student-centred learning and critical thinking skills, it also enables the cultivation of problem solving skills, improves communication, and maximises learning opportunities - all these skills are essential for the achievement of lifelong learning. Actively seeking collaboration with other agencies and workers should be part of everyday practice for all health professional. Collaborative working is central to contemporary health promotion practices and yet is often fraught with difficulties. One approach is to foster the effectiveness of inter-professional education and 
learning in partnership working. The format and style of the workshop induced a thought-provoking atmosphere, where sharing and exploring of problems and strategies was apparent but also the enthusiasm of the educational and practice staff made it a worthwhile learning experience.

The small number of community nursing students limited the study. The results may be specific to a particular course and context and should not be generalized. Further enquiry to examine whether interdisciplinary learning does promote collaboration in mental health practice is suggested.

\section{Acknowledgment}

Nessie Shia and Veronica Bankole would like to thank the community health-nursing students for their participation and nursing colleagues for their helpful comments. 


\section{References}

Barr, H (2002) Inter-professional Education: Today, Yesterday and Tomorrow. www.healthitsn.ac.uk/miniproject/Hugh Barr Final. Htm

Bell, J. (2005) Doing Your Research Project. A Guide For First Time Researchers in Education, Health and Social Science. $4^{\text {th }}$ Ediction, Open University Press, UK

Biggs, J. (2003) Teaching for Quality Learning at University. Buckingham: SRHE \& Open University Press Uses problem-based learning to illustrate 'constructive alignment' within a model which emphasises the need to align learning objectives, learning and teaching methods and assessment.

Biley, F., Smith, K. (1998) The buck stops here: accepting responsibility for learning and actions after graduation from a problem-based learning nurse education curriculum. Journal of Advanced Nursing 27 (5), 1021-1029.

Carey, L. and Whittaker, K. (2002) Experience of problem-based learning: issues for community specialist practitioner students. Nurse Education Today (22): 661-668.

Close and Cheater (1994) Utilization of Nursing Research. Journal of Advance Nursing. 19 pp762-773.

Cohen, L., Manion, L., Morrison, K. (2000) Research Methods in Education, $5^{\text {th }}$ Edition London and New York: Routledge Falmer

Conner, C., Reeves, S. (1997) Ways forward for shared learning between nursing and social work studies. Nurse Education today 17(6): 494-501.

Darvill, A. (2003) Testing the water - problem-based learning and cultural dimensions. Nurse Education in Practice 3, 72-79.

Department of Health (1999b) Making a difference: Strengthening the nursing, midwifery and health visiting contribution to health and healthcare. London, DOH. 
Department of Health (2000) The NHS Plan. HMSO London.

Department of Health (2001) Working together, learning together. A framework for lifelong learning for the NHS. Stationary Office: London

Department of Health (2001) Health Visitor Practice Development Resource Pack, London, Department of Health

Department of Health (2004) Choosing Health: Making Healthy Choices Easier. London HMSO

Department of Health (2006) Our Health, Our Care, Our Say. A new direction for community services. London, Stationery Office.

Eccles T. ( 1996) Succeeding with change: Implementing Action - Driven strategies, London. The McGraw-Hill companies

Elwyn G., Greenhalge T. and McFarlane F. (2001) Groups: A guide to small group work in Health, Management, education and Research. Abingdon, Radcliffe Medical Press

Gibbs, G. (1988) Learning By doing. A guide to teaching and learning methods, Further Education Unit, Oxford polytechnic (now Oxford Brookes University), Oxford.

Griffiths, S. Houston, K. \& Lazenbtsh, A. (1996) Enhancing Student Learning through Peer Tutoring in Higher Education. University of Ulster, Coleraine.

Hayward, K.S., Powell, L.T., McRoberts, J. (1996) The utility of external performance measurement tools in program evaluation. Rehabilitation Nursing: 23(1):8-11.

Kolb, D.A. (1984) Experiential Learning. Experience as the source of Learning and development. Prentice-Hall, Englewood Cliffs, NJ. 
Latimer, E., Deakin, A., Ingram, C., O’Brien, L., Smoke, M. \& Wishart, L. (1999) An interdisciplinary approach to a day-long palliative care course for undergraduate students. Canadian Medical Association Journal, 161(6) 720-731.

Leucht., R.M., Madsion, M.K., Taugher, M.P. \& Petterson, B..J. (1990) Assessing professional perceptions. Design and validation of an interdisciplinary education perception scale. Journal of Allied Health, 19 (2), 181-191.

Luker, P. (1989) Academic staff development in universities with special reference to small group teaching (unpublished $\mathrm{PhD}$ thesis) University of Nottingham.

MacDonald, N. (1996) Limits to multi-disciplinary education. Journal Palliative Care, 12 (2): 6.

Marshall, L., Rowland, F. (1998) A Guide to Learning Independently. ( $3^{\text {rd }}$ ed). Open University Press, Buckingham.

McPherson, K. Hendrick, L. \& Moss, F. (2001) Working and learning together: good quality care depends on it, but how can we achieve it? Quality in Health Care 10 (suppl. II) 46-53.

Miller, C., Freeman, M. and Ross, N. (2001). Interprofessional Practice in VHealth and Social Care; Challenging the shared learning agenda. Arnold, London.

Morrison, S., Boohan, M., Jenkins, J., Moutray, M. (2003) Facilitating undergraduate interprofessional learning in health care: Comparing classroom and clinical learning for nursing and medical students. Learning in Health and Social Care, 2, 92-104. Blackwell Publishing Ltd.

Nicol, M. \& Chaput de Saintonge, M. (2002) Learning clinical skills: an interprofessional approach. In: multi-Professional Learning for nurses (eds. S. Glen $\&$ T. Leiba). Palgrave, Basingstoke. 
Nursing \& Midwifery Council (NMC) (2004) Standards of proficiency for specialist community public health nurses.

Poldre, P.A. (1998) Collaboration in Health Care: Medical Students' Perceptions, Observations and suggestions. Toronto, University of Toronto.

Reynolds, F (1997) To what extend are first year students' attitudes towards PBL influenced by seminary group dynamics? International Conference on problem-based learning 'Changing to PBL'. Brunel University.

Reynolds, F. (2003) Initial experiences of Interprofessional problem-based learning: a comparison of male and female students' views. Journal of Interprofessional Care, Vol. 17, No1.

Schwartz, S. (2004). Time to bid goodbye to the psychology lecture. Personal Space. The Psychologist. Vol. 17, No1.

Wanless, D (2002) Securing Our Future Health: Taking a Long Term View. HM Treasury: London.

Wilkie, K (2000) The nature of problem-based learning. In: Glen S, Wilkie K (Eds). Problem-Based Learning in Nursing: A Model For a New Context. Macmillian, London

Wisker, G. (2002) The Postgraduate Research handbook. Succeed with your MA, MPhil, EdD and PhD. Palgrave Study Guides.

World Health Organisation (2004) Prevention of Mental disorder: effective interventions and policy options: summary report. Geneva: Prevention Research Centre of the Universities of Nijmegen and Maastricht.

World Health Organisation (2007) Mental Health, management and depression. www.who.int/mental_health / management / depression / accessed October 2007 
